\title{
Perfection of the programming design for medical college internship files with the utilization of android mobile phone client
}

\author{
Xiao-Meng Liu ${ }^{1, \mathrm{a}}$, Chang-Guo Xu ${ }^{1, \mathrm{~b}}, \mathrm{Ju}_{\mathrm{Wang}}{ }^{1, \mathrm{c}}$, Xiao-Lin $\mathrm{Hu}^{1, \mathrm{~d}}$, and Seng $\mathrm{Li}^{2, e^{*}}$ \\ ${ }^{I}$ Shandong Medical College, Jinan Shandong China

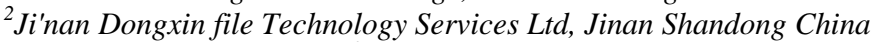 \\ Emai: ${ }^{a}$ landy3330@163.com, ${ }^{b} x u c h g @ s d m c . n e t . c n,{ }^{c}$ wangj@sdmc.net.cn, \\ ${ }^{d}$ huxlin@sdmc.net.cn, ${ }^{e}$ lisen674@163.com \\ *Corresponding author
}

\begin{abstract}
This paper describes the design of the medical intern students' file program, which utilizes the universal application of Android mobile clients to solve the hard problems from the collection of the students' files after they enter the internship places, mainly including the three aspects: the program overview, the technology and the function.

Keywords: Android Mobile Clients; Medical Students Internship; Students Program Design.
\end{abstract}

\section{Introduction}

Students of medical colleges will go to hospitals or other medical and health institutions for probation and internship of one year or two, After they fulfill the study of basic theoretical knowledge and skills. During this period, because the students are distributed to different internship places in different areas, it is quite difficult to conduct the internship management. The collection of students' internship situations and the construction of files cannot be completely done in time, either. In order to strengthen the intern management and file construction, based on the currently extensive application of Android mobile phone client among teachers and students, Android mobile phone internship file management system has been developed to improve the management of medical college students on interns, thereby helping to collect the internship information and perfect students' files.

\section{Overview of Program}

The design of the program aims to collect the information of the students in the internship places during the internship and send the real-time feedback to the school server as well as link the information with students' file management 
system so as to perfect the management of students' files. The paper mainly introduces how the computer design of Android mobile phone client system receiving the information is connected with the school students' file management system. No more details will be described here as different schools use different file management systems.

Generally, when the medical college students practice in a hospital or any other internship places, the institution will respectively require the staff of the departments, where the students will serve, to take charge of the management of the internship. In this paper, the staff in charge of the internship management in the internship places such as hospital will be called as Hospital Tutors. The medical schools will appoint several teachers to manage the internship students. By areas, each teacher will usually take care of the students from several internship institutions. In this paper, the medical school teachers in charge of the internship students will be called as School Tutors.

We intend to utilize Apache+mysql+php pattern to establish the system, which includes two parts of client and server. To be specific, it includes the client construction, server construction, data sheet setting and the function design, which contains the part of students, part of Hospital Tutors and the part of School Tutors.

\section{Technology}

\subsection{Generalization of the software design}

\subsubsection{Foundation of realization}

i. Realization of Android mobile phone network communication

Android sdk has lots of practical units which can realize the interaction with web server. As to $\underline{T C P}$ protocol, it has Socket which can apply set Entity to submit the data of client to the server. Regarding HttpResponse, it can use Execute way to obtain the data returned by web server.

ii. Realization of Servlet and jdbc technologies

Servlet is a class of java programming language. Web server enlarges the application program through servlet, in which doGet and doPost are used to receive the request of users and response to the client.

The main function of Servlet is to realize control. It can promptly send response message to the client, to realize the $\mathrm{C}$ of MVC pattern.

$J d b c$ refers to java database connection. It provides the unified access standard for various relational database. By using it, there are many methods for getting access to the database. Considering the practicability and the convenience, the paper utilizes the thin pattern to accomplish the database 
access. Meanwhile, Class for Name is applied to load the driver. Next, the Connection object and Statement object are established. Also, these objects are used to implement SQL sentence with excuteUpdate method or executeQuery method. Finally, it uses ResultSet object to get the information sent back from the database, as shown in the following figure.

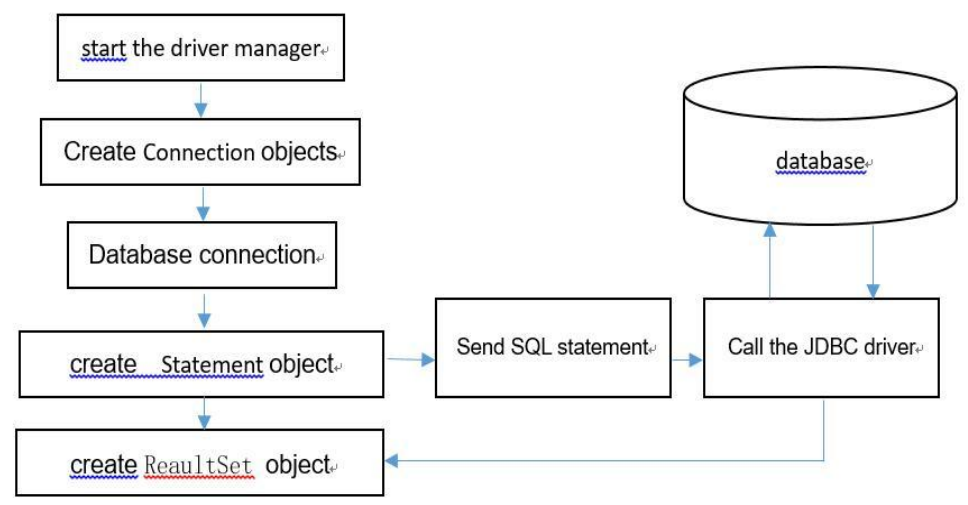

Fig. 1 Implementation process of Servlet and JDBC Technology

3.1.2. Realization of mobile phone client

i. Overview

It is realized by using eclipse and java language with the relevant plug-in. The interface display is accomplished by activity. It is responsible for receiving various operations conducted by users on the mobile phone. Because the realization process is not the key point of this paper, it will not be much described.

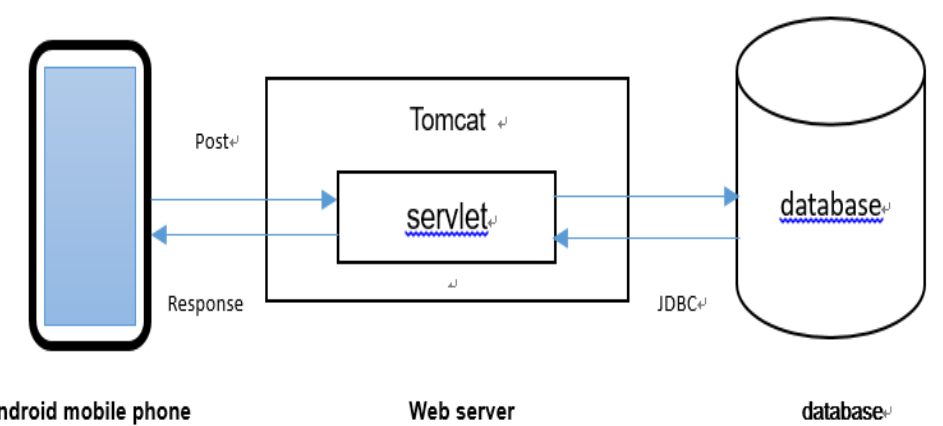

Fig. 2 Program design architecture 


\section{ii. Realization of modules}

The HttpPost object is applied to realize the data receiving and delivering, during which the encapsulation of the data delivered and the separation of the data received are completed with this object. It shields the hypertext transfer protocol. Hence, List $<$ NameValuePair $>$ is utilized for the data encapsulation and the data submission to the server. Finally, through the way of execute of HttpResponse, the data is received.

\subsubsection{Realization of Web server}

\section{i. Overview}

Web server uses tomcat6.0 as the servlet vessel. It is realized through the use of myeclipse and the establishment of Servlet through java language. The initial module mainly accomplish the deployment of Web application program and intercept the request of the mobile phone client. In the case of normal running, as long as the web server starts working, it can be realized.

ii. Query module

The query module is used to inquire data of all aspects of the internship software. After the query is submitted, the background will make up sql sentence according to the query condition. The execution module checks the database in accordance with $s q l$ and then feedbacks the information which can be shown to users in the tabular form. The data can be printed.

iii. Adding or editting module

The module is utilized to add the information of students, teachers and internship.

iiii. Statistics module

The module can establish different query modes according to various statistical patterns. It can also use sql sentence execution module to graphically present the data returned, which can help to conducts the statistical analysis on various internship situations.

iiiii. Sql sentence execution module

The createStatement of Connection is applied to establish Statement. And then it uses executeQuery to inquire statements.

\subsection{Database Design}

The database stores a variety of data and information of the software, including forms for the students, forms for the Hospital Tutors, forms for the School Tutors, the internship information forms and the internship situation forms. 
Tab.1students

\begin{tabular}{|c|c|c|}
\hline Field name & Description & Field type \\
\hline Id & Student table primary key & Numerical model \\
\hline Sid & Student ID & Character \\
\hline Name & Full Name & Character \\
\hline department & Department & Character \\
\hline Professional & Major & Character \\
\hline Sex & Sex & Character \\
\hline Age & Age & Numerical model \\
\hline Grade & Grade & Numerical model \\
\hline Unit & Practice Institution & Character \\
\hline City & City of the Institution & Character \\
\hline Pid & Practice ID & Numerical model \\
\hline
\end{tabular}

Tab.2 Hospital Tutor

\begin{tabular}{|c|c|c|}
\hline Field name & Description & Field type \\
\hline Id & $\begin{array}{c}\text { Hospital Tutor Table primary } \\
\text { key ID }\end{array}$ & Numerical model \\
\hline Name & Full name & Character \\
\hline Unit & Working Institution & Character \\
\hline Department & Department & Character \\
\hline Sex & Sex & Character \\
\hline Post & Post & Character \\
\hline Age & Age & Numerical model \\
\hline
\end{tabular}

Tab.3School Tutor

\begin{tabular}{|l|l|l|}
\hline Field name & Description & Field type \\
\hline Id & $\begin{array}{l}\text { School Tutor table primary } \\
\text { key ID }\end{array}$ & Numerical model \\
\hline Tid & Teacher ID & Character \\
\hline Name & Full name & Character \\
\hline department & Department & Character \\
\hline Sex & Sex & Character \\
\hline Post & Post & Character \\
\hline Age & Age & Character \\
\hline
\end{tabular}


Tab.4 Internship Information

\begin{tabular}{|c|c|c|}
\hline Field name & Description & Field type \\
\hline Id & $\begin{array}{c}\text { Internship information table } \\
\text { primary key ID }\end{array}$ & Numerical model \\
\hline Pid & Practice ID & Character \\
\hline Name & Practice name & Character \\
\hline Stid & Association of School Tutor \\
Table & Character \\
\hline Utid & $\begin{array}{c}\text { Association of Hospital Tutor } \\
\text { Table }\end{array}$ & Character \\
\hline Unit & Practice Institution & Character \\
\hline City & City of the internship & Character \\
\hline Begin & starting time of Internship & Character \\
\hline End & End time of Internship & Character \\
\hline
\end{tabular}

Tab.5 Internship situation

\begin{tabular}{|l|l|l|}
\hline Field name & Description & Field type \\
\hline Id & $\begin{array}{l}\text { Internship information table } \\
\text { primary key ID }\end{array}$ & Numerical model \\
\hline Note & Description of practice & Character \\
\hline Note_time & submission time of Internship & Character \\
\hline Note_person & Name of Submitter & Character \\
\hline
\end{tabular}

\section{Function}

\subsection{Students end}

The students end is quite simple. It only needs to reflect the problems of internship. The students information is not registered by students themselves. It is added through the computer end.

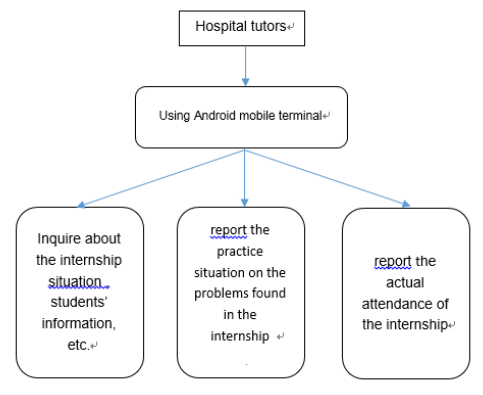

Fig. 3 Operation Process of Student End 


\subsection{Hospital Tutors end}

The hospital tutors can use the mobile phone to inquire the internship situation and regularly, according to the regulation of the school, report the internship situation and attendance situation.

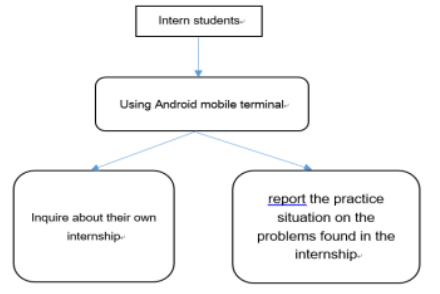

Fig. 4 Operation Process of Hospital Teacher

\subsection{School Tutors end}

The school tutors can check multiple internship information of students, whom they are responsible for, and further can carefully refer to the information of each student and regular attendance situation as well as the problems revealed.

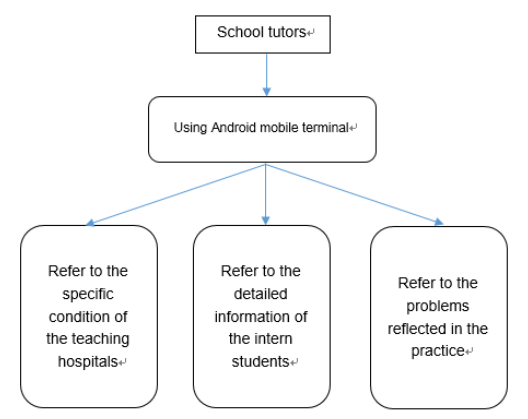

Fig. 5 Operation Process of School Teacher

\subsection{Computer end}

The function of the computer end includes the addition and management of basic information, statistics of internship situation and output of internship data.

a) The contents added and managed contain students' information, hospital and school tutors' information and internship information.

b) Statistics function. Aiming at the different query conditions, it makes the statistics on query results, such as the internship situation of some department in one year, or the statistics of internship situation under the guide of a certain internship tutor. 


\section{Summary}

With the design given above, we can help the medical colleges and universities to make the interns' information in the internship institutions better collected, to strengthen management, and to improve the internship files, so that the original intension of the program will be basically achieved.

\section{References}

1. Fanping Deng, In-depth understanding of Android(Vol.1),Machinery Industry Press, China, 2011.

2. Yafeng $\mathrm{Wu}$, Typical examples and project development of Android programming,Publishing House of Electronics Industry, China, 2011.

3. Chao Han, Development of Android classic application program, Publishing House of Electronics Industry, 2012.

4. Ning Li, Authoritative guide to Android Development, People's Posts and Telecommunications Press, 2011. 